\title{
Research on Effective Thermal Conductance of the Microbolometer
}

\author{
L. Zhang, C. Chen, T. Wang, Y. Zhao \\ Affiliations State Key Laboratory of Electronic Thin films and Integrated Devices \\ University of Electronic Science and Technology \\ China
}

\begin{abstract}
A three-level model of microbolometer was established by the software of intellisuit. Device thermal conductance Gdev, effective thermal conductance Geff and the theoretical value of device thermal conductance Gthe can be obtained by means of dynamic thermal finite element simulation, dynamic thermoelectric coupling finite element simulation and theoretical calculations respectively. And then the three parameters mentioned above were analyzed and conclusion can be drawn that effective thermal conductance Geff extracted not only can provide some important references for design of microbolometer, but also be more accurate in performance estimating of the device.
\end{abstract}

Keywords-a three-level model; microbolometer; finite element simulation; device thermal conductance; effective thermal conductance; dynamic thermoelectric coupling

\section{INTRODUCTION}

The operation of microbolometer is the absorption of IR radiation leading to the temperature of sensitive area increasing with $\Delta \mathrm{T}$, and the temperature change is converted into an electrical signal [1-2]. It is widely used in military and civilian market for its small size, light weight, low power consumption and room temperature operation [3-4]. Fig. 1 is a uncooled vanadium oxide microbolometer SEM photos of $28 \mathrm{um}$ pixel size L-type single layer of BAE company [5].

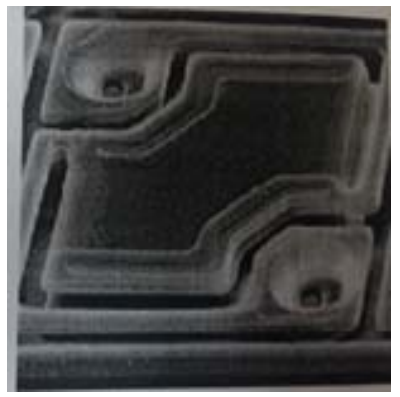

FIGURE I. THE SEM PHOTO OF L-TYPE SINGLE LAYER UNCOOLED VANADIUM OXIDE MICROBOLOMETER.

The noise Equivalent temperature difference (NETD) is one of important performance parameters in microbolometer and is defined as eqn (1) $[2,6]$ :

$$
N E T D=5 \cdot V_{n} \cdot \sqrt{G_{e f f}^{2}+w^{2} C^{2}} \cdot R_{0} \cdot C_{\text {int }} / \tau_{0} \cdot A_{d} \cdot \alpha \cdot \eta \cdot V_{\text {fid }} \cdot T_{\text {int }} \cdot(\partial P / \partial T)_{\Delta \lambda}(1)
$$

Where $\mathrm{V}_{\mathrm{n}}$ is the total noise, $\tau_{0}$ is The optical transmittance, $A_{d}$ is area of detector element, $C_{i n t}$ is integrating capacitor, $T_{\text {int }}$ is integrating time, $\mathrm{C}$ is the total heat capacity, $\mathrm{G}$ is thermal conductance, $\eta$ is Infrared absorption rate, $V_{\text {fid }}$ is bias voltage, $R_{e}$ is resistance of device, $\omega$ is modulation rate, thermal conductance $\mathrm{G}$ is also proportional to NETD. Device thermal conductance $\mathrm{G}_{\mathrm{dev}}$ is the thermal conductance of microbolometer when there is no bias on the device, and it can be calculated by eqn (2) [6]:

$$
G_{d e v} \approx 2 \cdot \sum k_{i} \cdot \frac{S_{i}}{l_{i}}
$$

Where $\mathrm{k}_{\mathrm{i}}$ is the thermal conductance of each of the bolometer leg-materials, $\mathrm{S}_{\mathrm{i}}$ is the cross sectional area of each of the bolometer leg-materials, and $1_{i}$ is the length of the bolometer legs.

Effective thermal conductance $\mathrm{G}_{\text {eff }}$ is the thermal conductance of microbolometer which can be changed by the bias current or voltage on the device, and it is defined eqn (3) [7]:

$$
G_{\text {eff }}=G_{d e v}-\alpha \cdot I_{0}^{2} \cdot R_{e}
$$

Where $I_{0}$ is bias current, $R_{e}$ is device resistance, $\alpha$ is temperature coefficient of resistance. Therefore, calculation of device thermal conductance and effective thermal conductance, which are got from eqn (2) and eqn (3), are approximately result for the result of the membrane is difficult to be precisely stated. In this paper, precise result of effective thermal conductance $\mathrm{G}_{\text {eff }}$, device thermal conductance are studied by finite element simulation. $G_{\text {eff }}$ is proved to be more accurate in reflecting the effective thermal conductance of real device.

\section{ANALYSIS OF THERMAL CONDUCTANCE}

\section{A. Theoretical Value of Device Thermal Conductance}

$\mathrm{G}_{\text {the }}$ is mainly fit for microbolometer vacant structures, and high performance IRFPA are packaged in vacuum [9-10], so $\mathrm{G}_{\text {the }}$ can be approximately expressed as eqn (4) [8-9]:

$$
G_{\text {the }} \approx 2 \cdot \sum k_{i} \cdot \frac{S_{i}}{l_{i}}
$$

Where $k_{i}$ is the thermal conductance of each of the bolometer leg-materials, $\mathrm{S}_{\mathrm{i}}$ is the cross sectional area of each of the bolometer leg-materials, and $l_{i}$ is the length of the bolometer legs. 


\section{B. The thermal Conductance Gdev and Effective Thermal Conductance Geff}

$\mathrm{G}_{\mathrm{dev}}$ and $\mathrm{G}_{\mathrm{eff}}$ can be obtained by finite element simulation, the former is device thermal conductance without loading bias current. The latter is effective thermal conductance under loading bias current, which is proportional to loading bias current (when the temperature coefficient of resistance is negative) [8]. And thermal conductance G can be written as eqn (5)

$$
G=\frac{C}{\tau}
$$

Where $\tau$ is thermal time constant. $\mathrm{C}$ is the total heat capacity, which is expressed as eqn $(6)[6,8]$ :

$$
C=\Sigma V_{i} \cdot \rho_{i} \cdot c_{i}
$$

where $\mathrm{V}_{\mathrm{i}}$ is the volume of each of the bolometer membrane, $\rho_{i}$ is the density of each materials and $c_{i}$ is the mass specific heat of each materials. The total heat capacity $\mathrm{C}$ can be calculated from three-level model of microbolometer, and thermal time constant $\tau$ can be read out by finite element simulation. Thus $\mathrm{G}$ can be obtained by eqn (5).

\section{MODELING, THEORETICAL CALCULATION AND FINITE ELEMENT SIMULATION}

In order to compare and analyse three kinds of thermal conductance in more detail, we establish a single L-type uncooled three-level microbolometer model, which the pixel size is $37 \mathrm{um} \times 37 \mathrm{um}$, the $\mathrm{VO} 2$ sensitive element resistance temperature coefficient is- 0.02 . Then $\mathrm{G}_{\text {the }}$ can be obtained by eqn (4) based on the model, and $\mathrm{G}_{\mathrm{dev}}$ can be got by FEA method. Meanwhile $\mathrm{G}_{\text {eff }}$ can be achieved by dynamic thermoelectric coupling FEA method.

\section{A. Modeling}

Three-level model of microbolometer is established by intellisuit mems software, Two-level mask should be designed before it is imported the actual mems process, then define the thickness of the layers so that three-level model can be generated. Import process line material parameters to corresponding structure layers before the force field, electric field, thermal field integrated simulation can be done. The layout and three-level structure of microbolometer which are shown in fig. 2(a), and fig. 2(b) are established by mems intellisuit software. This three-level model have a complete micro bridge structure, including absorbing layer $\mathrm{Si}_{3} \mathrm{~N}_{4}$, sensitive layer $\mathrm{VO}_{x}$, electrode layer $\mathrm{NiCr}$, support layer $\mathrm{Si}_{3} \mathrm{~N}_{4}$, the cavity substrate $\mathrm{Si}$, which are shown in fig. 2(c).

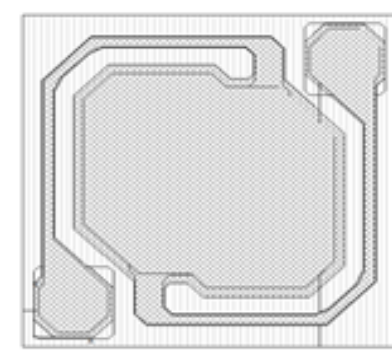

Figure 2: (a).

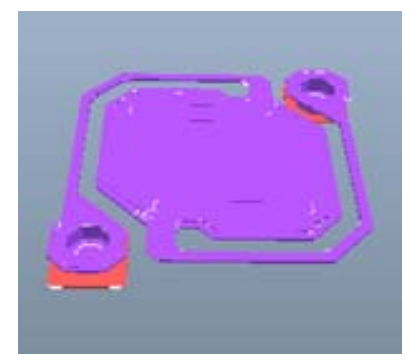

Figure 2: (b).
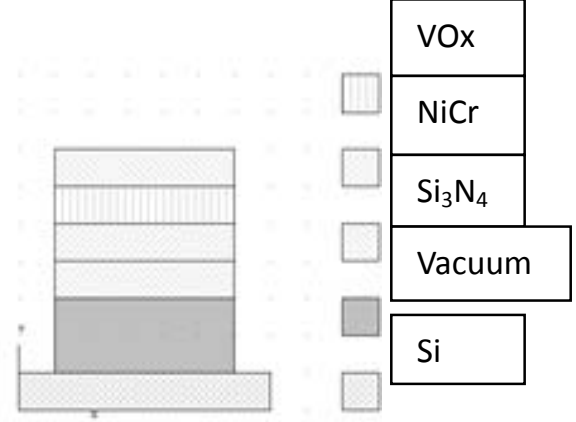

Figure 2: (c)

FIGURE II. (A) LAYOUT OF MICROBOLOMETER. (B) THE THREE-LEVEL STRUCTURE OF MICROBOLOMETER. (C) THE INTERFACE OF MICROBOLOMETER.

Properties of every layer are shown in table 1 and are imported to the model before finite element simulation

TABLE I. THE MATERIAL PARAMETERS OF DEVICE LAYERS [10-12].

\begin{tabular}{|l|l|l|l|}
\hline & $\mathrm{Si}_{3} \mathrm{~N}_{4}$ & $\mathrm{NiCr}$ & $\mathrm{VO}_{\mathrm{x}}$ \\
\hline Density $\left(10^{3} \mathrm{~kg} / \mathrm{m}^{3}\right)$ & 2.4 & 8.9 & 3.36 \\
\hline Conductivity $(\mathrm{J} /(\mathrm{cm} \cdot \mathrm{K}))$ & 0.045 & 0.907 & \\
\hline Specific heat J/(g/k) & 0.292 & 0.691 & 0.05 \\
\hline
\end{tabular}

\section{B. Theoretical Calculation and FEA}

1) The device thermal conductance $G_{\text {dev }}$ : The device thermal conductance $\mathrm{G}_{\mathrm{dev}}$ can be got by dynamic thermal finite element simulation $2.4 \times 10^{-11} \mathrm{~W} / \mathrm{cm}^{2}$ thermal impulse, which is shown in fig. 3(a), is loaded, and initial temperature is defined as $27^{\circ} \mathrm{C}$. Temperature gradient of the microbolometer structure is shown in fig. 3(b), and the device temperature versus time curve is shown in fig. 3(c). 


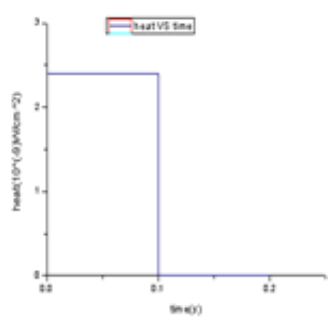

Figure 3:(a).

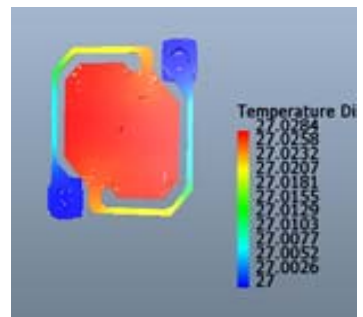

Figure 3: (b).

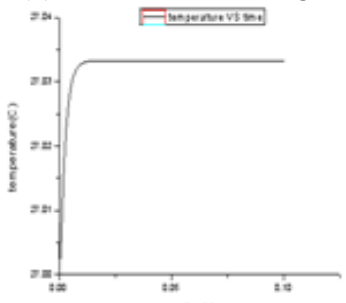

Figure 3:(c).

FIGURE III. (A) THERMAL RADIATION ENERGY VERSUS TIME CURVE. (B) TEMPERATURE GRADIENT OF THE MICROBOLOMETER STRUCTURE. (C)TEMPERATURE VERSUS TIME CURVE.

Thermal time constant $\tau$ is $2.63 \mathrm{~ms}$, which can be obtained by its definition from fig. 3(c), the total heat capacity $\mathrm{C}$ is $4.068 \times 10^{-10} \mathrm{~J} / \mathrm{K}$ by eqn (6), so $\mathrm{G}_{\mathrm{dev}}$ is $1.547 \times 10^{-7} \mathrm{~J} / \mathrm{K}$ by eqn $(5)$.

2) The effective thermal conductance: Since $G_{\text {eff }}$ varies with the bias current, couples of different bias current, range from $1 \times 10^{-6}$ to $4 \times 10^{-6}$ is loaded on the $\mathrm{NiCr}$ electrode of device in turn, during dynamic thermoelectric coupling finite element simulation, initial temperature is 27 . To ensure device temperature stabilized, a $20 \mathrm{~ms}$ thermal radiation impulse is delay for 40ms compared to the bias current on the surface of the three-level model. For example, bias current, which pulse mode is shown fig. $4(\mathrm{a})$, is $1 \times 10^{-6} \mathrm{~A}$. At the same time, thermal radiation energy, which pulse mode is shown in fig. $4(\mathrm{~b})$, is $2.4 \times 10^{-11} \mathrm{~W} / \mathrm{cm}^{2}$. Temperature gradient of the microbolometer structure shown in fig. 4(c), and temperature versus time curve of device is shown in fig. $4(\mathrm{~g})$. Thermal time constant $\tau$ could be obtained by its definition from fig. $4(\mathrm{~g})$. What's more, $\mathrm{G}_{\text {eff }}$ can be achieved by eqn (5). In the same way, load groups of bias current which are $2 \times 10^{-6} \mathrm{~A}, 3 \times 10^{-6} \mathrm{~A}, 4 \times 10^{-6} \mathrm{~A}$ are shown in fig. 4(a) respectively, while the remaining loads are constant. The temperature gradient of the microbolometer structure is shown in fig. 4(d), fig. 4(e), fig. 4(f) respectively, and their temperature versus time curve are shown fig. $4(\mathrm{~g})$, The $\mathrm{G}_{\text {eff }}$ versus current curve is shown in fig. 4(h). Specific simulation date are shown in table 2 .
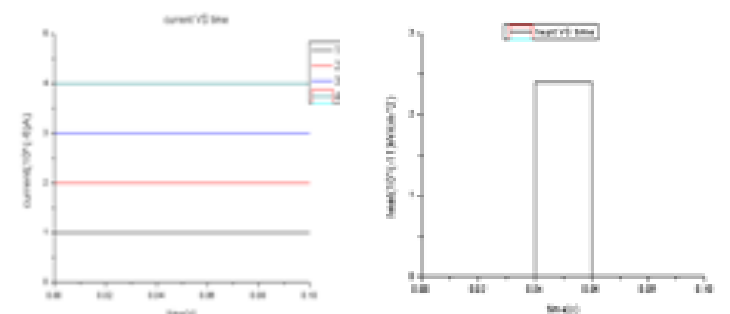

Figure 4(a).

Figure 4 (b).

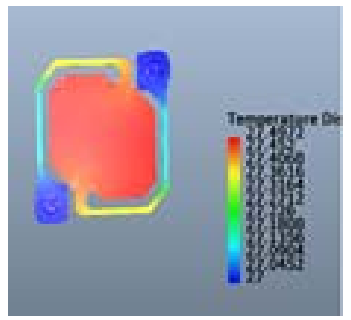

Figure 4(c).

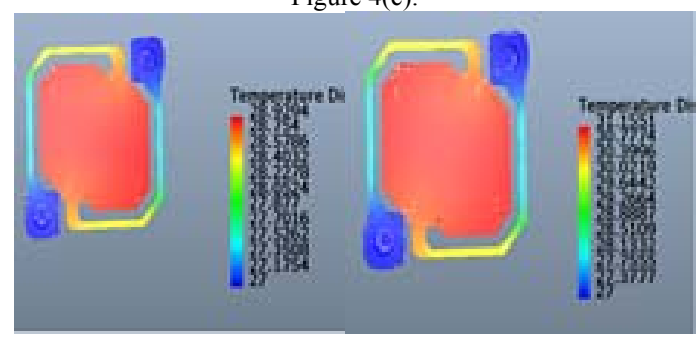

Figure 4(d). Figure 4 (e).

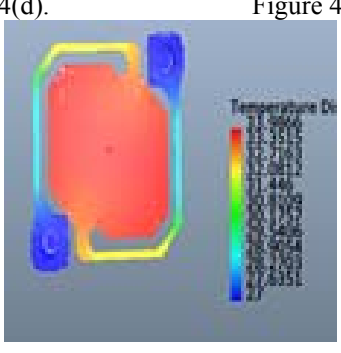

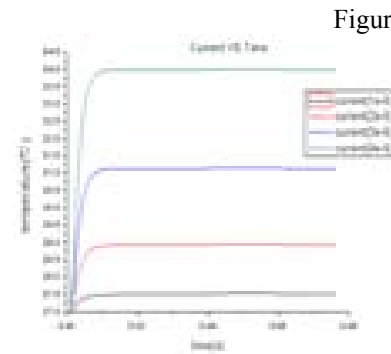

Figure 4(g).

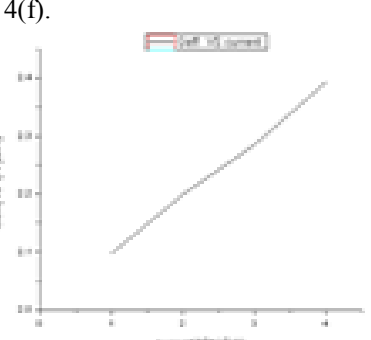

Figure $4(\mathrm{~h})$.
FIGURE IV. (A)CURRENT VERSUS TIME CURVE. (B)THERMAL RADIATION ENERGY VERSUS TIME CURVE. (C) TEMPERATURE GRADIENT OF THE MICROBOLOMETER STRUCTURE WHILE CURRENT IS $1 \times 10-6 \mathrm{~A}$. (D)TEMPERATURE GRADIENT OF THE MICROBOLOMETER STRUCTURE WHILE CURRENT IS 2×10-6A.

(E)TEMPERATURE GRADIENT OF THE MICROBOLOMETER

STRUCTURE WHILE CURRENT IS 3×10-6A. (F)TEMPERATURE GRADIENT OF THE MICROBOLOMETER STRUCTURE WHILE CURRENT IS 4×10-6A. (G)TEMPERATURE VERSUS TIME CURVE. (H) EFFECTIVE THERMAL CONDUCTIVITY VERSUS CURRENT CURVE. 
TABLE II. CURRENT AND EFFECTIVE THERMAL CONDUCTANCE.

\begin{tabular}{|c|c|c|c|}
\hline & $\begin{array}{l}\text { Curr } \\
\text { ent } \\
(10 \\
\left.{ }^{-6} \mathrm{~A}\right)\end{array}$ & $\begin{array}{l}\text { Thermal time } \\
\text { constant(ms) }\end{array}$ & $\begin{array}{l}\text { Effective thermal } \\
\text { conductance }\left(10^{-7} \mathrm{~J} / \mathrm{K}\right)\end{array}$ \\
\hline & 1 & 1.94 & 2.097 \\
\hline 2 & 2 & 1.85 & 2.199 \\
\hline 3 & 3 & 1.78 & 2.285 \\
\hline 4 & 4 & 1.70 & 2.393 \\
\hline
\end{tabular}

Therefore, it can infer that effective thermal conductance $\mathrm{G}_{\text {eff }}$ is proportional to the current, $\mathrm{G}_{\mathrm{dev}}$ is $1.547 \times 10^{-7} \mathrm{~J} / \mathrm{K}$. Meanwhile length and width of bridge legs of the device is obtained by measuring the two-level mask layout, and its thickness is got from three-level model, so the theoretical value of device thermal conductivity $\mathrm{G}_{\text {the }}$ is $2.98 \times 10^{-7} \mathrm{~J} / \mathrm{K}$ by eqn (4).

\section{CONCLUSION}

In this paper, the three-level simulation model of microbolometer was established by the software of intellisuit. Then $\mathrm{G}_{\text {the }}$ was got by eqn (4) and $\mathrm{G}_{\mathrm{dev}}$ was obtained by dynamic thermal finite element simulation. There were some differences by comparing with data, result from irregular bridge legs structure. Furthermore, dynamic thermoelectric coupling finite element simulation was done, and groups of effective thermal conductance under different bias current were obtained, which were proportional to the current. Therefore, effective thermal conductance is more accurate in reflecting the thermal conductance of the device while working, and it also provides some references for improving system performance of device and design of readout integrated circuit.

\section{REFERENCE}

[1] Sun, G. C., Ha T. J. \& Hyung, H. P., Effective heat conservation in a sandwich-structured micro bolometer using mesoporous TiO2. Sensors and Actuators, A 155, pp. 131-135, 2009.

[2] Hong, C. W., Xin, J. Y. \& Guang, H., IR microbolometer with self-supporting structure operating at room temperature. Infrared Physics\& Technology, 45, pp. 53-57, 2004

[3] Jerominek, H., Francis, P. \& Nicholas., Micro machined uncooled VOx based, IR bolometer array, SPIE, Vol. 2746. pp. 60-71

[4] Grossman, E.N , Nolen, S. \& Paulter., Concealed weapons detection system using uncooled, pulsed, imaging arrays of millimeter-wave bolometer. Proceedings of SPIE, Vol.4373, pp.7-15, 2001

[5] Backer, B.S., Butler, N. \& Kohin, K., Recent Improvements and Developments in Uncooled systems at BAE SYSTEM North America. proc. SPIE. infrared detectors and focal plane arrays, Vol. 4721, pp. 83-90, 2002

[6] Niklaus, F., Adit, D. \&Christer , J., Performance model for uncooled infrared bolometer arrays and performance predictions of bolometer operating at atmospheric pressure, Infrared Physics \& Technology, 51, pp. 168-177, 2008

[7] Xing Ding, L., Ping Zhi, L. \& Xue Chu, S., Analysis of bias heating effect in uncooled infrared microbolometer and determination of its main parameters, Infrared millimeter waves, 18(1), 1998.2.

[8] Eriksson, P., Andersson, J.Y. \& Stemme, G., Thermal characterization of surface-micro machined silicon nitride membranes for thermal infrared detectors. IEEE Journal of Micro electromechanical Systems , 6(1), pp. 55-61, 1997.

[9] Kevin, Liddiard, C. \& Reinhold, O., Test structures and performance analysis for uncooled resistance bolometer detector array. Part of the
SPIE conf. on infrared Detector and Focal Plane Arrays: Oriando, Florida, pp. 115-125, 1998.

[10] Murphy, D, Ray, M. \& Wyles, J., Performance improvements for $\mathrm{VO}_{\mathrm{x}}$ microbolometer FPAS. Proc . SPIE, Vol. 5406, pp. 531-540, 2004.

[11] Endo, R, Shima, M. \& Susa, M., Thermal conductivity measurement and predictions for NiCr solid solution. Alloy. IntJ. Thermo-phys, Vol. 31, pp. 1991-2003, 2010.

[12] Terada, Ohkubo, Y. \& Mohri, T., Thermal conductivity in nickel solid solutions. J. Appl. phys, 81(5), pp. 2263-2268, 1997. 